\title{
PEMANFAATAN INTERNET SEBAGAI SUMBER PEMBELAJARAN DAN KEMANDIRIAN BELAJARAN BAGI ANAK TIBAN LAMA
}

\author{
Yusli Yenni", Jemes Simatupang \\ Program Studi Teknik Informatika, Universitas Putera Batam \\ E-mail: yusliany10@gmail.com
}

\begin{abstract}
The development of computer technology now has developed very rapidly, almost all aspects of human life cannot be separated from the use of computer technology. Technological developments are also supported by the development of the internet for all people from young children to adults all using the internet to support activity activities. Technological developments can also be felt in the use of the internet as a learning medium. Learning achievement is a thing that cannot be separated from the activities of learning, because from the activities of good learning, good achievements are obtained. While the internet is a global communication media that connects computer components in computer networks throughout the world. Internet in the world of education can provide access such as online libraries, literature sources and access to learning materials can be accessed easily via the internet. Through the use of the internet in the world of education, it must be used maximally and wisely in its use so that there is no mistake in the use which can later damage the nation's young generation. In using the internet, it can also increase learning independence. Independence of learning is also needed to encourage students to run in initiative and encourage themselves to study continuously. Independence of learning also encourages to become a confident personality. Independence in learning also encourages students to learn in a discipline and full of confidence and no longer depend on others. With the internet, everyone can implement learning independence effectively and efficiently
\end{abstract}

Keywords: internet, learning independence, children

\begin{abstract}
Abstrak: Perkembangan Teknologi Komputer saat ini telah berkembang dengan sangat pesat, hampir seluruh aspek kehidupan manusia tidak terlepas dari pemanfaatan teknologi komputer. Perkembangan teknologi juga di dukungan perkembangan internet bagi semua kalangan mulai dari anak kecil sampai orang dewasa semua menggunakan internet untuk menunjang aktivitas kegiatan. Perkembangan teknologi juga dapat dirasakan dalam penggunaan internet sebagai media pembelajaran. Prestasi belajar merupakan hal yang tidak dapat dipisahkan dari kegiantan belajar, karena dari kegiatan belajaran yang baik maka didapatlah prestasi yang baik juga. Sedang internet merupakan sebuah media komunikasi global yang menghubungkan komponen-komponen komputer dalam jaringan-jaringan komputer diseluruh dunia. Internet dalam dunia pendidikan dapat menyediakan akses seperti perpustakaan online, sumber literatur dan akses materi pembelajaran dapat di akses dengan mudah dengan melalui internet. Melalui pemanfaatan internet dalam dunia pendidikan harus digunakan secara maksimal dan bijaksanaan dalam penggunaannya sehingga tidak terjadi kesalahan pemanfaatan yang nanti bisa merusak generasi muda bangsa. Dalam penggunaan internet juga bisa meningkatkan kemandirian belajar. Kemandirian belajar juga diperlukan untuk mendorong siswa agar berjalar secara inisiatif dan mamacu diri untuk belajar terus menerus. Kemandirian belar juga mendorong untuk menjadi kepribadian yang penuh percaya diri. Kemandirian dalam belajar juga mendorong siswa untuk belajar secara displin dan penuh percaya diri serta
\end{abstract}


Jurdimas (Jurnal Pengabdian Kepada Masyarakat) Royal

Vol. 2 No. 1, Jan 2019, hlm. 7 - 12

ISSN 2614-7912 (Print)

DOI: https://doi.org/10.33330/jurdimas.v2i1.278

ISSN 2622-3813 (Online)

Available online at https://jurnal.stmikroyal.ac.id/index.php/jurdimas

tidak lagi bergantungan kepada orang lain. Dengan internet semua orang bisa menerapkan kemandirian belajar dengan efektif dan efisien.

Kata kunci : internet, kemandirian belajar, anak-anak

\section{PENDAHULUAN}

Perkembangan teknologi pada saat ini sangat berkembang dengan sangat pesat dalam memenuhi kebutuhan kehidupan manusia. Perkembangan teknologi tersebut juga dirasakan dalam dunia pendidikan khusus dalam proses pembelajaran. Dalam sistem pendudukan sudah menggunakan teknologi dalam proses belajar mengajar yang dilakukan. Menurut Makagiansar (1996) pada abad ke-21 sistem pendidikan akan mengalami pergeseran atau perubahan paradigma, diantaranya adalah dari kampanye buta aksara ke kampanye buta teknologi, budaya dan komputer. Selanjutnya menurut Surya (1998) salah satu karakteristik pendidikan pada abad ke-21 adalah penggunaan berbagai inovasi IPTEK terutama media elektronik, informatika dan komunikasi dalam berbagai kegiatan pendidikan. (Usodo, Kurniawati, \& Kuswardi, 2016).

Perkembangan teknologi pada saat ini sangat berkembang dengan sangat pesat dalam memenuhi kebutuhan kehidupan manusia. Perkembangan teknologi tersebut juga dirasakan dalam dunia pendidikan khusus dalam proses pembelajaran. Dalam sistem pendudukan sudah menggunakan teknologi dalam proses belajar mengajar yang dilakukan. Menurut Makagiansar (1996) pada abad ke-21 sistem pendidikan akan mengalami pergeseran atau perubahan paradigma, diantaranya adalah dari kampanye buta aksara ke kampanye buta teknologi, budaya dan komputer. Selanjutnya menurut Surya (1998) salah satu karakteristik pendidikan pada abad ke-21 adalah penggunaan berbagai inovasi IPTEK terutama media elektronik, informatika dan komunikasi dalam berbagai kegiatan pendidikan. (Usodo, Kurniawati, \& Kuswardi, 2016)

Penggunaan teknologi berbasis internet sangatlah berpengaruh dalam proses belajar dan mengajar. Penggunaan teknologi internet haruslah digunakaan secara bijak karena jika salah dalam penggunaan akan berdampak terhadap tindakan kejahatan atau kriminalitas nantinya. Internet atau interconnected network adalah sebuah sistem komunikasi global yang menghubungkan komputer-komputer dan jaringanjaringan komputer diseluruh dunia. Internet menghubungkan situs akademik, pemerintahan, komersial, organisasi,maupun perorangan. Internet menyediakan akses layanan telekomunikasi dan sumber daya informasi untuk jutaan pemakainya yang tersebar diseluruh dunia(Wati, 2014). Melalui pemanfaatan internet ini dalam pendidikan memberikan dampak yang sangat besar untuk mencari informasi yang berhubungan dengan mata pelajaran yang diajarkan disekolah. Internet juga bisa memberikan kemandirian belajar karena internet memberikan 


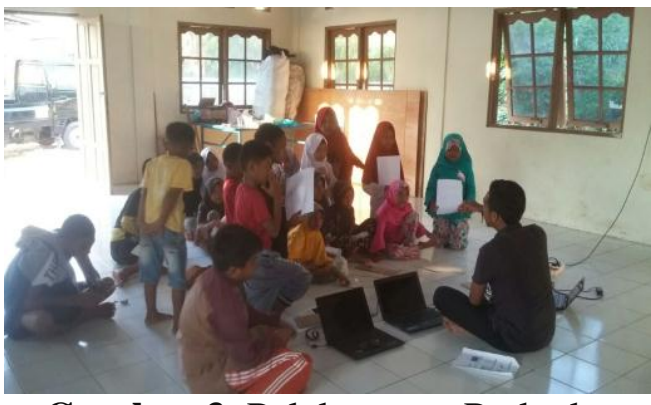

Gambar 3. Pelaksanaan Praktek

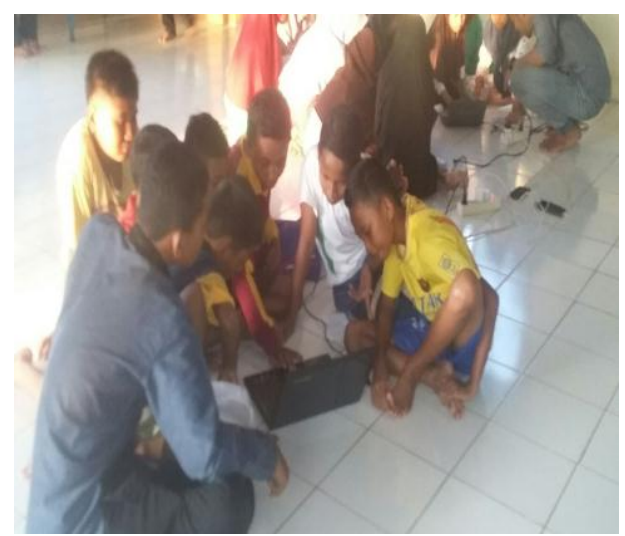

Gambar 4. Pelaksanaan Praktek

\section{Evaluasi Pelaksanaan Kegiatan}

Evaluasi Pelaksanaan kegiatan Pembinaan Pemanfaatan Internet Sebagai Sumber Pembelajaran Dan Kemandirian Belajaran Bagi Anak Di Tiban Lama Rt 02 Rw 08, dilihat dari hasil pembandingan Quisioner Pra test pada hari pertama yang akan dilakukan sebelum kegiatan penyampaian materi dan dibandingkan dengan hasil praktek pada pelatihan ini di hari kedua. Diharapkan pada pelaksanaan praktek hari kedua para peserta dapat lebih memaksimalkan pemanfaatan internet sebagai media pembelajaran untuk penyiapan materi belajar. Pembinaan yang akan dilakukan oleh pengabdi akan dilanjutkan dengan memonitor peserta dan membantu mengembangkan kemampuannya dalam penggunaan Pemanfaatan
Internet Sebagai Sumber Pembelajaran Dan Kemandirian Belajaran Bagi Anak Di Tiban Lama Rt 02 Rw 08.

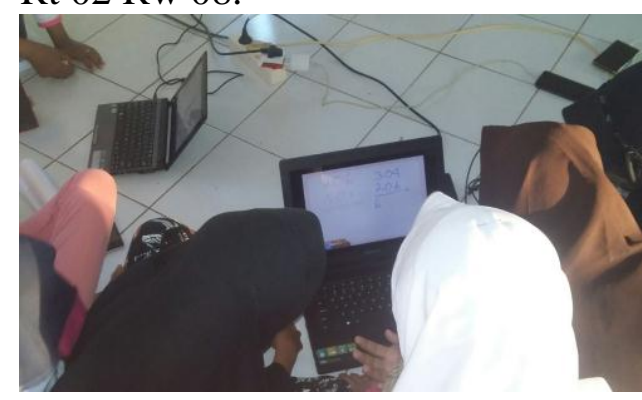

Gambar 5. Evaluasi kegiatan

\section{PEMBAHASAN}

Untuk melihat tingkat kesuksan dari pengabdian ini dapat dilihat dari hasil pelaksanaan program pengabdian masyarakat terhadap masyarakat dalam Pemanfaatan Internet Sebagai Sumber Pembelajaran Dan Kemandirian Belajaran Bagi Anak Di Tiban Lama Rt $02 \mathrm{Rw} 08$ yaitu sebagai berikut :

1. Setiap respon dari peserta pembinaan ini akan dinilai secara observasi selama pembinaan ini berlangsung dengan cara mengadakan diskusi yang menyakut pembahasan dari pengabdian ini.

2. Pembinaan ini dapat meningkatkan keterampilan peserta pengabdian ini yang dinilai melalui tugas-tugas tentang cara mengakses internet untuk pembelajaran.

3. Peserta pembinaan ini masih duduk di sekolah dasar yang mengikuti pengabdian ini harus mampu belajar mandiri dengan menggunakan media internet sebagia pendukungnya.

4. Dalam pengabdian ini peserta pembinaan juga diajarkan 
Jurdimas (Jurnal Pengabdian Kepada Masyarakat) Royal

Vol. 2 No. 1, Jan 2019, hlm. 7 - 12

ISSN 2614-7912 (Print)

DOI: https://doi.org/10.33330/jurdimas.v2i1.278

ISSN 2622-3813 (Online)

Available online at https://jurnal.stmikroyal.ac.id/index.php/jurdimas

bagaimana menggunakan
internet untuk mencari bahan-
bahan pelajaran $r$ untuk
menyelesaikan tugas serta
contoh bahan ujian.

Untuk mencapai kesuksan dalam pengabdian ini maka dibuatlah rincian dalam pelaksanaan pengabdian ini. Adpun rincian dalam pelaksana pengabdian ini di mulai dari tahap persiapan sampai tahap pelaksanaan, dapat kami sampaikan temuan-temuan sebagai berikut:

1. Ketua RW 008 tiban lama menyampaikan harapan untuk program pengabdian ini bisa dilaksanakan secara berskala di tahun berikutnya.

2. Situasi dan kondisi pembinaan yang dilakukan sangatlah kondusif serta memberikan kenyamanan bagi peserta pembinaan karena pelaksanaan dilakukan di ruangan balai pertemuan warga yang ada di RW 008 dan RT 02 di tiban lama sehingga peserta bebas berinteraksi dengan pemanteri.

3. Materi pembinaan yang di berikan berdasarkan pembahasan yang dilakukan dengan menggunakan bahasa yang mudah dipahami. Materi pembinaan ini akan menambah wawasan dan pengetahuan tentang internet dalam membantu pembelajaran sehingga bisa menciptakan kemandiran belajar setiap individunya .

4. Peserta pembinaan dapat mengetahui kelebihan dan kerugian dalam mengakses internet. Agar para anak-anak di tiban tidak salah dalam menggunaka teknologi internet.

5. Peserta pembinaan dapat menerapkan kemandirian dalam belajar sehingga tidak bergantung terhadap orang lain dalam menyelasaikan setiap tugas-tugas sekolah nantinya.

\section{SIMPULAN}

Hasil dari pengabdian pembinaan ini yang diberikan kepada anak-anak di tiban lama dapat ditarik kesimpulan bahwa pembinaan tentang internet untuk pembelajaran cukup berhasil dimana peserta pembinaan bisa mengimplementasikan hasil pembelajaran tentang internet untuk mencari materi-materi sekolah serta dapat menyelesaikan tugas yang disekolahan. Serta peserta pembinaan juga bisa menerapkan kemandiran belajar sehingga tidak bergantung terhadap orang lain dalam mengerjakan pekerjan rumah atau tugas-tugas sekolah. Dengan adanya anak-anak di tiban lama bisa mandiri dalam belajar serta bisa menyelasaikan tugas sekolah dengan internet.

\section{Daftar Pustaka}

Setiyani, R. (2010). Pemanfaatan Internet Sebagai Sumber Belajar. Pemanfaatan Internet Sebagai Sumber Belajar Rediana Setiyanil, V(2), 117133.

Usodo, B., Kurniawati, I., \& Kuswardi, Y. (2016). Pelatihan Penerapan Beberapa Aplikasi Dari Microsoft: Office Mix , 
Jurdimas (Jurnal Pengabdian Kepada Masyarakat) Royal

Vol. 2 No. 1, Jan 2019, hlm. 7 - 12

ISSN 2614-7912 (Print)

DOI: https://doi.org/10.33330/jurdimas.v2i1.278

ISSN 2622-3813 (Online)

Available online at https://jurnal.stmikroyal.ac.id/index.php/jurdimas

Onenote , Sway Dalam

Pembelajaran Bagi Guru-Guru

Matematika, 4(9).

Wati, Ajeng Fika Fatma Candra. (2014). Hubungan Pemanfaatan Internet Sebagai. Hubungan Pemanfaatan Internet Sebagai Sumber Belajar Dan Kemandirian Belajar Dengan Prestasi Belajar Sosiologi Siswa Kelas Xi Sma Negeri Kebakkramat Tahun Pelajaran 2013/2014 Skripsi. 